AperTO - Archivio Istituzionale Open Access dell'Università di Torino

Memory distortions: When suggestions cannot be easily ignored

This is a pre print version of the following article:

Original Citation:

Availability:

This version is available http://hdl.handle.net/2318/1711586

since 2019-09-11T10:27:49Z

Published version:

DOI:10.1002/acp.3597

Terms of use:

Open Access

Anyone can freely access the full text of works made available as "Open Access". Works made available under a Creative Commons license can be used according to the terms and conditions of said license. Use of all other works requires consent of the right holder (author or publisher) if not exempted from copyright protection by the applicable law. 


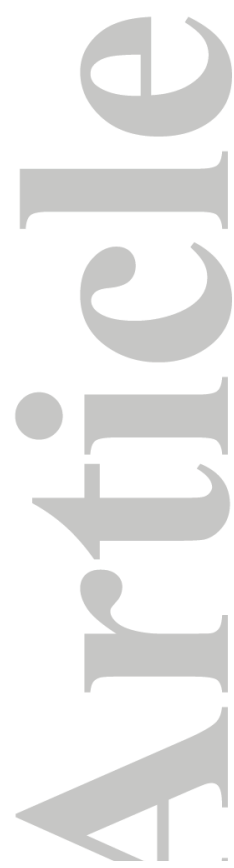

Cabalo Donna Gift (Orcid ID: 0000-0001-9568-1723)

\section{Memory distortions: when suggestions cannot be easily ignored}

Orhantepe Mahallesi, Turgut Özal Bulvarı, No: 21, Dragos, 34865 Kartal/İstanbul, Turkey

\section{Donna Gift Cabalo}

Istanbul Şehir University

\section{Francesco Ianì}

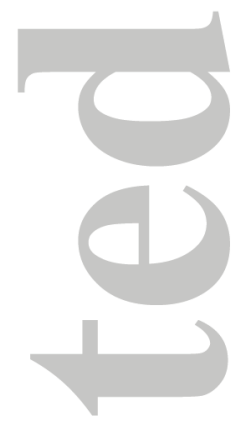

Turin University

Via Giuseppe Verdi, 8, 10124 Torino TO, Italy

\section{A. Reyyan Bilge}

Istanbul Şehir University

Orhantepe Mahallesi, Turgut Özal Bulvarı, No: 21, Dragos, 34865 Kartal/İstanbul, Turkey

Giuliana Mazzoni

University of Hull

Cottingham Rd, Hull HU6 7RX, UK

This article has been accepted for publication and undergone full peer review but has not been through the copyediting, typesetting, pagination and proofreading process which may lead to differences between this version and the Version of Record. Please cite this article as doi: 10.1002/acp.3597 


\begin{abstract}
In the present study, the persistence of personal false memories (FM) after social feedback that denies their truth was assessed with a procedure similar to Nash, Wade and Lindsay (2009b). Participants imitated actions performed by the experimenter (Session 1) and watched a doctored video with performed and critical "fake" actions (Session 2), followed by a memory rating and a recognition task. A few days later (Session 3) participants were clearly told that some memories were false and received daily reminders of the correct list of objects/actions before testing their memory again in Session 4. Results of both memory ratings and recognition indicated effective FM implantation. Interestingly, response times for correct rejections were longer for fake than true objects, suggesting participants struggled to ignore false suggestions. Crucial for our aim, Session 4 showed that FM persisted also after the debriefing and repeated presentations of correct list of objects/actions, suggesting that FM for actions are rather difficult to discard.
\end{abstract}

Keywords: false memories; persistence of false memories; action memory. 


\section{Introduction}

People can spontaneously report false memories about autobiographical experiences (e.g., Mazzoni, Scoboria, \& Harvey, 2010), claiming to remember events that never really happened or remember things in a way that is different from how they actually occurred. Many studies have also shown that autobiographical false memories can be easily induced with a variety of experimental procedures (for a discussion see e.g., Laney \& Loftus, 2013), which capitalize on the reconstructive nature of memory retrieval (e.g., Bartlett, 1932; Conway, 1997; Katz, 1989; Loftus, 2005; Schacter, Coyle, Fischbach, Mesulam, \& Sullivan, 1995; Wade, Garry, Read, \& Lindsay, 2002). For example, false memories can be easily induced via suggestions (e.g., Hyman, Husband, \& Billings, 1995; Loftus \& Pickrell, 1995; Mazzoni, Loftus, Seitz, \& Lynn, 1999 Scoboria, Mazzoni, Kirsch, \& Milling, 2002); imaginative procedures (e.g., Garry, Manning, Loftus, \& Sheramn, 1996; Mazzoni \& Memon, 2003), forward and backward inferences (e.g., Brewer \& Treyens, 1981; Hannigan \& Tippens Reinitz, 2001), plausibility manipulations (e.g., Hart \& Schooler, 2006; Johnson \& Raye, 2000; Mazzoni, Loftus, \& Kirsch, 2001), the replacement of forgotten items with new ones (e.g., McCloskey \& Zaragoza, 1985), etc. (for an outline of the processes involved in the creation of false memories, see Mazzoni \& Kirsch, 2002).

While most studies have focused on the processes and conditions involved in the creation of false memories, the question of their persistence has raised much less interest (e.g., Otgaar, Candel, Merckelbach \& Wade, 2009; Otgaar, Scoboria and Smeets, 2013). However, after experimentally creating false memories, one fundamental research issue is to understand whether they are long-lasting and persist after the debriefing. In other words, are debriefings successful? Do participants disavow and discard these false memories? This is the main aim of 
the present study. Specifically, we examined whether a very clear and targeted debriefing on the falsity of these memories help people

identify false memories as false.

In the next sections, studies on the duration of false memories will be briefly reviewed, and the effect of debriefing after the implantation of false memories will be examined more thoroughly. We will then introduce the procedure of false memory implantation that will be used in the current study.

\section{False memories: persistence}

Ours is not the first study to examine the duration of false memories. For example, when a misinformation procedure was used to induce false memories, about half of the implanted false memories were found one and a half years later, and at the same rate as true memory (Zhu et al., 2012). Similarly, Huffman, Crossman and Ceci (1997) found that even after two years, half of the children tested in a previous study by Ceci, Huffman, Smith and Loftus (1994) still assented to at least one of the false events originally implanted. These results suggest that even a brief exposure to misinformation can lead to long-term false memory (seemingly, the strength of memory trace was similar for true and false memories). False memories can then persist after a long delay. False memories for actions might be even longer lasting than false memories induced by repeated exposure to misinformation, as in the Zhu et al., (2012) case and in the case of the repeated interviews used by Ceci et al. (1994). If the credibility that comes with doctored visual information is a key factor, as suggested by Nash et al. (2009a), then we might find that this type of false memory is rather likely to survive both time and the debriefing procedure. In addition, the Nash et al. (2009a) procedure creates multiple false memories, thus increasing the likelihood of observing false memories after one week and after people are told that these memories were false. 


\section{False memories: the effect of debriefing}

Previous studies have also reported mixed findings on the effectiveness of debriefing.

The pioneering study of Loftus and Pickrell, 1995) on false memory implantation reported some notable comments of the participants to the debriefing. The false memories were created by providing participants with detailed information about four episodes from their childhood.

Participants were convinced that all these events had been given to the experimenter by older relatives. Only three events were true. The other one was the false event about getting lost in a shopping mall. A reliable percentage of participants developed a false memory for this event. In the debriefing, it was stated that in fact the getting lost event had not been provided by the relatives, while the true ones had. Interestingly, it was observed that some participants continued to claim they remembered getting lost in the shopping mall even after debriefing. More recently, Otgaar, Candel, Merckelbach and Wade (2009) also reported that some child participants claimed to remember a false event even after the debriefing was given, although, again, no memory tests assessed the effect of the debriefing, and just remarks made by participants after the experiment were reported. In their study, Otgaar et al. (2009) examined whether prevalence information, that is reports on the frequency of an implausible event, can promote in children false memories for an implausible event. Participants received prevalence information in the form of a false newspaper article about a true (e.g., almost choking on a candy) or a false event (e.g., abducted by a UFO). The authors found that prevalence information increased the number of false memories in 7-8year old children. Crucially, an extensive number of children were extremely surprised during the debriefing when they were told that the false event had not happened to them. For instance, one 8-year old child responded, 'It really did happen' and another one said, 'I really can remember seeing the UFO' (Otgaar et al., 2009, p.120). More in general, after the debriefing, 39\% of the children were absolutely convinced that they had experienced the false events. These findings suggest that the false 
memories in this study were resistant to the debriefing session. In a more recent work, Otgaar, Scoboria and Smeets (2013) examined in adults and children how belief and memory of childhood events change after debriefing. Participants were presented with true (visit to a theme park) and false (hot air balloon ride) narratives and interviewed twice within the course of two weeks. After the second interview, participants were debriefed and rated their memory and belief for the true and false events, along with memory characteristics. After one month, only the adult participants rated again their memory and belief about the true and false events, and provided details about their memories. In the first interview, participants were asked to report all the details they could recall about each event, and to focus and try again if no memories were recalled (lack of memory was explained as being normal). Context reinstatement and guided imagery were also used to create the false memory, and participants were asked to think about the narratives daily for one week. The procedure induced false memories, which were reported in both interviews (in 32\% and 36\%, respectively). Interestingly, when assessed one month later, participants, $9 \%$ of the sample still reported false memories, which persisted after the debriefing. The authors concluded that the debriefing is rather effective in adults.

However, Otgaar et al. (2013) also found that the debriefing, in some cases, affected the belief in the occurrence of the event more than the memory itself, thus creating what have been called as non-believed memories (more on non-believed memories later; see also Mazzoni, Scoboria \& Harvey, 2010). This suggests that in some cases the debriefing might be only partially effective. In addition, in the Otgaar et al. (2013) study, only one false memory was experimentally created. What happens when multiple and rather strong false memories are created instead? Compared to assessing just one false memory in a study, examining multiple false memories helps get greater statistical precision data. Moreover, it has also applied implications. In the forensic setting, for example, poor interviewing techniques can distort the memory of witnesses in multiple ways (Bruck, Ceci, \& Hembrooke, 1998; Fisher, Geiselman, 
\& Raymond, 1987; Loftus, 1979; Loftus \& Palmer, 1974; Zaragoza, Payment, Ackil, Drivdahl, \& Beck, 2001), and might induce a variety of false memories for personal events (Chrobak \& Zaragoza, 2013; Kassin et al., 2010; Leo \& Davis, 2010; Loftus, 1979; Shaw \& Porter, 2013). It is important to assess the persistence of multiple false memories, and whether witnesses, for example, can easily identify them as false and thus reject them when they receive a clear feedback that these memories are indeed false.

\section{Procedure used to create multiple false memories}

Multiple false memories can be experimentally created for non-performed actions (Nash, Wade, \& Lindsay, 2009b). The procedure proposed by Nash et al. (2009b) stems from previous findings showing that doctored visual evidence (e.g., doctored photos , Wade, Garry, Read, \& Lindsay, 2002) provides perceptual information that is easily mistaken as true, and thus tricks the monitoring system (Johnson, Hastroudi, \& Lyndsay, 1993) into classifying unexperienced events as experienced (Lindsay, Hagen, Read, Wade, \& Garry, 2004).

In the original study of Nash et al. (2009b) on false memories for actions, each participant observed and performed simple actions while being filmed. After the participant left, the RA filmed himself performing 2 of the 4 critical fake actions. The critical fake actions were doctored using a split-screen method, wherein clips from true actions (i.e., participants observing the RA performing actions) were combined with the critical fake actions. The final doctored videos showed the participant watching the experimenter performing the fake action. The participants then returned 2 days after the initial session and watched a 4-minute video sequence containing 10 original clips and 2 clips portraying the doctored critical fake actions. The subjects were divided into three groups. Self + RA subjects watched themselves observing the RA performing true and critical fake actions. The RA-only subjects viewed clips that contained only the RA performing the same actions as the Self+RA group, this time themselves not included. Stranger-only subjects viewed a stranger performing true and critical fake actions 
in a different room setting. After watching the video sequence, the participants were asked to imagine actions that were presented in the monitor for $10 \mathrm{~s}$. A total of 15 actions were imagined, 2 of which were critical actions: one previously presented in the video sequence (video + imagine) and the other was not presented (imagine only). The participants then completed the Autobiographical Beliefs and Memory Questionnaire (Scoboria, Mazzoni, Kirsch, \& Relyea, 2004), containing 12 performed actions, 2 critical fake actions (not performed but watched in the video), 2 control actions (not performed nor watched) and 12 new actions. They were asked to rate their belief and memory for each action on a 1-8 scale ( 8 highest rating). The participants were then debriefed and guessed which of the actions were fake. Higher ratings (and thus more false memories) were obtained in the Self+RA group, compared to RA-only or Stranger-only groups, and overall higher ratings for false than true actions were observed, indicating that being exposed to doctored (false) visual evidence can create false beliefs and memories. A very similar procedure was used also in a study by Clark, Nash, Fincham and Mazzoni (2012), confirming that in the Self+RA group false memories for actions can be obtained.

Nash, Wade and Brewer (2009a), found that by manipulating the nature of false evidence, enhanced familiarity and imagery alone are insufficient to cause large memory distortion effects, whereas the credibility of the false evidence seems to play a crucial role. Doctoring a video provides this credibility because it is evaluated as a credible source of information.

\section{The present study}

In the current study, a slight modification of the Nash et al. (2009b) procedure was used to create multiple false memories for actions. Participants first imitated a number of actions performed by the experimenter on objects (Session 1). In Session 2, they watched a doctored video containing both a subset of performed actions ("true" actions) and, crucially, critical "fake" actions, that the participants had not performed. Participants then rated their belief and 
memory for the true, the fake, and completely new actions (namely, actions never performed in session 1 and never seen in session 2). In Session 2 they also performed a recognition task in which they were presented with pictures of objects (true, fake and new) and for each one they were asked to respond, as fast and accurately as possible, whether during the first session they had or had not performed an action with it. One to five days after the recognition task, participants were fully debriefed (Session 3) and were told that some objects presented in the videos had not been presented in Session 1 (i.e., actions related to those objects were not performed). In other words, participants were clearly told that some (false) memories were false. We aimed to obtain very persistent false memories in Session 3 to avoid the potential criticism that the effect of debriefing could be attributed to the weak nature of the false memories representation. For this reason, between Session 2 and 3 participants were asked to repeatedly imagine the entire set of performed and fake actions, in line with previous arguments (Nash et al., 2009b) that presenting the doctored evidence in combination with imagination might lead to an additive effect, thus enhancing the strength of the false memories. Between Session 3 and Session 4, when the final memory tests were administered, the debriefing was enhanced by sending one email per day containing the list of true objects only. This was done to ensure the debriefing was not forgotten and to increase its effectiveness. Session 4 was held one week after Session 2, and participants again rated their belief and memory for all types of actions and completed the recognition task.

While adopting an existing procedure, there were some novel elements in our study compared to Nash et al. (2009b) and to Otgaar et al. (2013). First, while Nash et al. (2009b) assessed the effect of the doctored videos using only subjective belief and memory ratings, the current study also included a recognition task. Confident false recognition indicates that people accept the object they recognize as one with which they had performed an action (confident false recognition can indicate either the creation of false memories for actions or a change in 
response criteria that make people accept the item as old). We also recorded response times, which allows for the assessment of hesitations in correct rejections and thereby examine whether suggestions can be easily ignored by participants. Second, and in line with the study by Otgaar et al. (2013) and Clark et al. (2012), we also assessed whether debriefing created non-believed memories, which are memories with a vivid sense of recollection that are no longer believed (NBMs; Mazzoni et al, 2010). NBMs indicate that debriefing decreases the belief in the veridicality of the memory, while affecting significantly less the memory representation itself, which in several cases keeps the characteristics of a recollective experience (see Scoboria, Boucher, \& Mazzoni, 2015). To assess NBMs, in Sessions 3 and 4 we used a variation of the procedure by Clark, Nash, Fincham and Mazzoni (2012) (see also Mazzoni, Clark, \& Nash, 2014). In the original study, the authors presented the debriefing and the questionnaires approximately 4 hours after Session 2, and detected a sizeable percentage of non-believed memories. In our procedures we split Clark et al.’s (2012) Session 3 into two different sessions, the debriefing session (our Session 3) and a new test session (our Session 4). Furthermore, we expanded the time interval between Session 2 and the debriefing phase (from 4 hours to a few days).

Unlike Otgaar et al. (2013), we examined the effect of debriefing and the existence of NBMs for multiple recent actions, and not for one single past complex experience. The recency of the events and their relative simplicity, as well as the daily presentation of the list of true objects might enhance the effectiveness of the debriefing. However, as already stated, the strength and multiplicity of false memories created with the doctored video, as well as the repeated imagination before the debriefing, might increase the likelihood of creating false memories that persist over time despite the debriefing. 
To sum up, in this study, we first aimed at replicating the main finding (false memories for actions) obtained by Nash et al. (2009b) by assessing not only subjective ratings but also accuracy and response times in a recognition task in which true, fake and new objects were presented. If the videos create false memories, as claimed by Nash et al. (2009b), one should observe lower accuracy for fake compared to new objects. Furthermore, if information in the doctored video cannot be easily ignored, response times for correct rejections of fake objects should be higher than those for completely novel objects. The effect on response times can be due either to the presence of a strong false memory (i.e., a good mental representation that feels somewhat like a true memory), or to false information interfering with decision processes, or both. In any case, it would suggest that participants struggle to ignore the effect of the experimental manipulation even when the false memory is identified as false and correctly rejected. Second, we assessed whether multiple false memories for actions persist after a clear, enhanced debriefing and across a relatively long time-interval (i.e., 1 week). This can be revealed by relatively high memory and belief ratings, and a lower rate of correct rejections for fake objects compared to completely novel objects. Finally, we examined whether this procedure created NBMs.

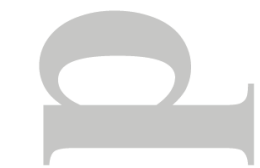

\section{Method}

\section{Participants}

Sixty-one undergraduate students from Istanbul Şehir University taking the Introduction to Psychology course completed all four sessions of the study. There were 50 women and 11 men, and their ages ranged from 18-26 $(M=20.33, S D=1.47)$. They were compensated with course credits for their participation. The research was approved by the Institutional Review Board at Istanbul Şehir University, Istanbul, Turkey. 


\section{Materials}

We selected 32 common-use objects (see Appendix A). Of these, 6 were fillers and were presented in all sessions to all participants. Of the remaining 26 , two were novel fillers and presented to all participants only in the recognition task. The remaining 24 were divided in three critical groups, 'true', 'fake, and 'new', used for all analyses and counterbalanced across participants. Fillers (e.g., screwdriver, wine opener) were objects which had been presented and with which all participants had performed an action (e.g., twisting the screwdriver similar to tightening a screw, using a wine opener) in Session 1. Fillers appeared in the video sequence, the questionnaires and the recognition tasks. 'True' objects (e.g., mobile phone, teaspoon) were objects on which both the experimenter and the participants had performed an action (e.g., picking up the mobile phone, mixing using a teaspoon) in Session 1. They were then presented for recognition in Session 2 (pre-debriefing) and 4 (post-debriefing). Fake objects (e.g., keys, toothbrush) were used only by the experimenter during the filming of fake actions (e.g., opening a doorknob with a key, brushing teeth with a toothbrush), and then presented for recognition in Session 2 (pre-debriefing) and 4 (post-debriefing). New objects (e.g., book, paperclip) were presented only in the recognition tasks (Sessions $2 \& 4$ ).

Participants also completed belief and memory questionnaire, which was the same as in Clark et al. (2012), with the only difference being that in our study the belief questionnaire was always completed first.

The questionnaire contained a list of 20 objects, 4 true, 4 fake, 4 new, 6 fillers old and 2 filler novel objects. It was composed of a belief part and a memory part, with a brief introduction explaining the distinction between belief and memory. Beliefs were defined as the conviction that something happened in a person's past even in the absence of any memory for it. Memories were defined as a clear picture 'in your head' about an event. To further explain 
the difference of belief and memory, participants were presented examples. Participants were told that we believe we were born even if we don't remember the event in itself; we believe we had breakfast on a certain day 10 years ago because we always have breakfast, not because we have a specific memory (i.e., what did we eat for breakfast or where was I sitting) for that specific breakfast. For each object participants were asked to rate how strong they believed (1no belief, to 8 -strong belief) or remembered (1-no memory, to 8-strong memory) performing each action. Demographic data were also collected (age, handedness and years of schooling). The recognition task on the same 20 objects was completed using E-prime software 2.0.

\section{Design}

This is a within-participant, 3 (Type of Objects: true, fake and new) x 2 (sessions: pre vs post debriefing) design.

\section{Procedure}

The experimental procedure is a variant of the one ideated by Nash et al. (2009b) and by Clark et al. (2012). All participants went through four sessions. Session 1 and 2 were separated by two days, session 3 was held 2-5 days after Session 2 and Session 4 one week after Session 2. The four sessions were run individually.

Session 1. The participants were informed that the study was about imitating actions. They were told that the researcher would perform actions on objects for 12 seconds each (each action performed three times) and the participants' task was to carefully observe and imitate the action afterwards. They were also informed that the entire session would be filmed assuring the confidentiality of the video. After getting informed consent, the researcher and the participant sat at a table facing each other. All 'true' and filler objects were placed inside a box located on the table, at the researcher's side. The researcher began taking out one object at a time and carried out a pre-determined action with it (e.g., shaking a small box, writing with a 
pencil). The participant was to observe and imitate the action on the object. This observe-copy task continued until all 14 objects ( 8 presented and 'true' and 6 fillers) in the box were used.

Participants were then thanked, asked to come back 2 days later for Session 2 and told not to talk about the experiment with friends and classmates. Immediately after the participant left the laboratory, the researcher returned to the table with the same setting and started filming herself performing actions with the fake objects. The same set-up and position of the camera was maintained.

Video-editing. The doctored videos were edited using Adobe After Effects. To make the participants believe that they had performed actions with the fake objects, we edited out the parts in which the participant was imitating the action. We then combined the parts of the genuine video of Session 1, in which the participant was passively observing the researcher performing actions with objects, with the fake video where the researcher was carrying out actions with the four fake objects that had not been used before (see Figure 1). In all videos, the researcher was shown while performing actions to objects while the participant was observing. The video sequence was created using MovieMaker, each clip separated by a 5 second blank screen. The video sequence was composed of 18 clips (14 presented objects -8 true and 6 fillers- and 4 fake).

Session 2. After 2 days, participants watched the doctored video sequence twice. To ensure that participants paid attention to the video sequence, in the first viewing, they were asked to write how many times per week they usually perform an action with the objects shown. In the second viewing, they verbally described what was happening in each clip (e.g., using a wine opener, wearing a scarf). Next, they solved anagrams for 2 minutes and were then asked to complete the belief and memory questionnaire. 
The recognition task followed. Participants were shown via E-Prime 2.0 photos of the same 20 objects presented in the questionnaire. For each, they were asked to answer the question, "Do you remember performing an action with this object?" as fast and as accurately as they could by pressing the B key for YES and the N key for NO; both keys were labelled. Photos of objects were presented for a maximum of $5 \mathrm{sec}$, separated by a blank screen $(1 \mathrm{sec})$ and by a fixation cross $(500 \mathrm{~ms})$. Each photo was presented twice (never in sequence) to obtain more reliable data for response times. Responses and response times were recorded by the computer. Session 2 ended by reminding the participants to come back a few days later for Session 3. Between Session 2 and 3, participants received daily emails with the list of objects (for both performed and fake actions), asked to think about carrying out an action with all the objects in the list, and to send a confirmation e-mail after completing the task. This was done to strengthen false memories for fake actions.

Sessions 3 and 4. In Session 3, participants were debriefed and were told that some of the clips they had watched in Session 2 were fake. The experimenter explicitly indicated which objects and performed actions were false. Specifically, the experimenter showed doctored clips to the participants and explained how they were created. The participants were told that the fake clips were filmed after they left the laboratory in Session 1 and were edited using a specific computer program. To enhance the effect of debriefing, after the debriefing, participants received the correct list once a day via email (i.e., between Sessions 3 and 4). Each time, participants were asked to think about carrying out an action with the objects in the list, and to send a confirmation e-mail after completing the task. On the 6th day, subjects came in for Session 4, the last and final session, and completed the same questionnaire and recognition task as in Session 2. At the end of Session 4, the experimenter debriefed participants with the true aim and nature of the study and thanked them for their participation. 


\section{Results}

All participants were included in the analyses. We ran a repeated measure 2 (Session pre- and post- debriefing) x 3 (Type of Object- true, fake, new) ANOVA for each dependent variable of interest: belief ratings, memory ratings, accuracy and response times. Table 1 shows the mean Belief, Memory and Accuracy Ratings and the mean Response Times.

\section{Belief Ratings}

The results of the overall $2 \times 3$ repeated measures ANOVA on belief ratings showed a significant main effect of Type of Object (Greenhouse-Geisser correction; $F(1.70,102.04)=$ $\left.337.08, p<.001, \eta_{\mathrm{p}}{ }^{2}=.85\right)$, with participants giving higher belief ratings for true $(M=7.53$, $S D=.96)$ than fake $(M=3.23, S D=2.52)$ and new objects $(M=1.75, S D=1.69)$ (see Table 1$)$. In addition, there was also a significant main effect of Session $\left(F(1,60)=47.35, p<.001, \eta_{\mathrm{p}}{ }^{2}=\right.$ $.44)$, with Session 2- pre debriefing $(M=4.76, S D=2.94)$ being higher than Session 4- post debriefing $(M=3.58, S D=3.08)$. These main effects were qualified by a significant interaction between Type of Object and Session $\left(F(2,120)=30.20, p<.001, \eta_{\mathrm{p}}{ }^{2}=.34\right)$. Results revealed higher ratings for used objects than fake objects $(t(121)=17.07, \mathrm{p}<.001$, Cohen's $d=1.55$; used objects were also rated higher than the new objects $(t(121)=29.79, \mathrm{p}<.001$, Cohen's $d=2.71$. Interestingly, fake objects received higher ratings than new objects, $t(121)=7.55, p<.001$, Cohen's $d=.69$. As shown in Table 1 , while there was no change in belief for true objects before and after the debriefing, there was a significant decrease over sessions in belief for fake and new objects. This was confirmed by the post hoc t-tests comparing the two sessions across all types of objects. While true objects did not differ in belief ratings between pre- and postdebriefing $(t(60)=-.39, p=.70$, Cohen's $d=-.05)$, both fake and new objects were rated higher in Session 2 than in Session $4,(t(60)=7.51, p<.001$, Cohen's $d=0.96$ and $\mathrm{t}(60)=$ $4.05, p<.001$, Cohen's $d=.52$; respectively). 
To further analyze the interaction, we also conducted separate ANOVAs and t-tests for Session 2 (pre-debriefing) and Session 4 (post-debriefing). In Session 2, before the debriefing, a repeated measures ANOVA revealed significant differences in belief ratings for each type of $\operatorname{object}\left(F(2,120)=114.60, p<.001, \eta_{\mathrm{p}}^{2}=.66\right)$. Post-hoc comparisons using the Bonferroni correction revealed that true objects were rated higher than fake, $(t(60)=8.25, p<.001$ Cohen's $d=1.06)$, and new objects, $(t(60)=15.56, p<.001$, Cohen's $d=2.00)$. Important for our aim, belief for fake objects was higher than for new objects, $(t(60)=6.54, p<.001$, Cohen's $d=.84)$, indicating that doctored videos significantly increased participants' belief in fake actions.

Also in Session 4, after the debriefing, the main effect of object type remained significant, (Greenhouse-Geisser correction; $\left.F(1.43,85.51)=582.81, p<.001, \eta_{\mathrm{p}}^{2}=.91\right)$. At the Bonferroni adjusted post hoc comparisons, true objects were rated higher than fake, $(t(60)=$ $21,48, p<.001$, Cohen's $d=2.77)$ and new objects, $(t(60)=37.33, p<.001$, Cohen's $d=4.81)$. Important to our aim, after the Bonferroni correction, ratings for fake objects remained significantly higher than new objects, $(t(60)=4.72, p<.001$, Cohen's $d=.61)$. These results suggest that false memories are still believed in even after the debriefing.

\section{Memory Ratings}

The $2 \times 3$ overall repeated measures ANOVA revealed a significant main effect of Type of Object (Greenhouse-Geisser correction; $F(1.74,104.47)=365.29, p<.001, \eta_{\mathrm{p}}{ }^{2}=.86$ ), with participants showing higher memory ratings for true $(M=7.50, S D=.93)$ than fake $(M=3.11$, $S D=2.53)$ and new objects $(M=1.70, S D=1.70)$, as shown in Table 1 . The main effect of session was also significant $\left(F(1,60)=38.32, p<.001, \eta_{\mathrm{p}}^{2}=.39\right)$, with Session $2(M=4.70, S D=2.99)$ being higher than Session $4(M=3.51, S D=3.06)$. A significant interaction qualified the main effects $\left(F(2,120)=31.42, p<.001, \eta_{\mathrm{p}}{ }^{2}=.34\right)$. True objects were rated higher than fake $(t(121)=$ 17.81, $<<.001$, Cohen's $d=1.62)$ and new objects $(t(121)=31.18, \mathrm{p}<.001$, Cohen's $d=2.83$. Fake objects received overall higher ratings than new objects, $(t(121)=7.38, p<.001$, Cohen's $d$ 
$=.67$ ). Similarly to belief, also for memory ratings, no decrease was observed between Session 2 and 4 for true objects, while a significant decrease was observed for fake and new objects. In order to analyze the interaction, we ran post hoc t-tests with Bonferroni correction comparing sessions across all types of objects. Similar to belief ratings, memory ratings for fake objects were higher in session 2, $(t(60)=7.26, p<.001$, Cohen's $d=.94)$, than in Session 4 . The ratings for new objects also significantly decreased in between sessions, $(t(60)=4.11, p<.001$, Cohen's $d=.54$ ), whilst ratings for true objects did not differ between pre and post debriefing $(t(60)=-.24, p=.81$, Cohen's $d=-.03)$.

To further analyze the interaction, we conducted separate ANOVAs and t-tests for Session 2 (pre-debriefing) and Session 4 (post-debriefing). In Session 2, before the debriefing, a one way repeated measures ANOVA revealed significant differences in memory ratings $\left(F(2,120)=118.27, p<.001, \eta_{\mathrm{p}}{ }^{2}=.66\right)$. Post-hoc comparisons (Bonferroni adjusted) showed that true objects were rated higher than fake $(t(60)=8.45, p<.001$, Cohen's $d=1.09)$ and new objects, $(t(60)=15.90, p<.001$, Cohen's $d=2.05)$. Important for our aim, memory for fake objects was higher than for new objects, $(t(60)=6.43, p<.001$, Cohen's $d=.83)$. These data show that doctored videos created memories for the fake objects.

Results were similar in Session 4, after the debriefing. The main effect of object type was significant, (Greenhouse-Geisser correction; $F(1.44,86.60)=713.38, p<.001, \eta_{\mathrm{p}}{ }^{2}=.92$ ). The Bonferroni corrected post-hoc comparisons showed that true objects were rated significantly higher than fake, $(t(60)=24.07, p<.001$, Cohen's $d=3.11)$, and new objects, $(t(60)=44.54, p<.001$, Cohen's $d=5.75)$. Importantly, fake objects were still rated higher than new objects, $(t(60)=4.46, p<.001$, Cohen's $d=.58)$, indicating that memories were still present for fake objects even after the debriefing, hence suggesting that these 'fake object/action memories' were hard to discount. 
We compared belief and memory ratings before and after the debriefing, in order to assess the frequency of non-believed memories, in which belief ratings are 1 or more points lower than memory ratings (Clark et al., 2012; Mazzoni et al., 2014). We found only 7\% of non-believed memories, which was too low to run a full analysis.

\section{Accuracy}

To evaluate how participants distinguished between signal and noise trials, we computed d', a measure of signal detection sensitivity (e.g., Green \& Swets, 1966) for both fake and new objects. For each participant, we calculated the proportion of hits ("yes" responses when the stimulus was a signal, i.e., true objects) and false alarms for fake objects ("yes" responses when the stimulus was a fake object), as well as false alarms for new objects ("yes" responses when the stimulus was a new object). The log linear approach was used to calculate hit and false alarm rates (Hautus, 1995).

A $2 \times 2$ analysis of variance (ANOVA) applied to the d' values across Session 2 and Session 4 showed a significant main effect of Type of Object $\left(F(1,60)=77.11, p<.001, \eta_{\mathrm{p}}{ }^{2}=.56\right)$. We also detected a main effect of session, $\left(F(1,60)=44.02, p<.001, \eta_{\mathrm{p}}{ }^{2}=.42\right)$. The interaction between Type of Object and Session was also significant, $\left(F(1,60)=37.98, p<.001, \eta_{\mathrm{p}}{ }^{2}=.39\right)$. Participants showed higher sensitivity for new objects $\left(d^{\prime}=2.85, M=2.85, S D=.69\right)$ compared to fake objects $\left(d^{\prime}=2.05, M=2.05, S D=1.25\right)(t(121)=-8.98, p<.001$, Cohen's $d=.81)$. Sensitivity (Bonferroni adjusted) was significantly higher in Session 4 ( $d^{\prime}=2.76, M=2.76$, $S D=.72)$ compared to Session $2\left(d^{\prime}=2.13, M=2.13, S D=1.28\right)(t(121)=6.22, p<.001$, Cohen's $d=.88$ ). This interaction was mainly due to the fact that, compared to Session 2 , in Session 4 sensitivity did not increase for new objects $(t(60)=-1.42, p=.16$, Cohen's $d=-.20)$, while it increased significantly for the fake ones $(t(60)=-7.08, p<.001$, Cohen's $d=-.96)$, indicating that after the debriefing participants were better able to detect false memories. 
At Session 2, a significant difference in sensitivity was detected between fake and new objects $(t(60)=-8.89, p<.001$, Cohen's $d=-1.24)$. Interestingly, the same result holds at Session $4(t(60)=-3.03, p<.01$, Cohen's $d=-.41)$ (both results are Bonferroni adjusted) thereby suggesting that false memories remain rather difficult to discard after the debriefing .

\section{Response Times}

Response times refer to hits for true object recognition, and correct rejections for fake and new object recognition. The overall $2 \times 3$ repeated measures ANOVA revealed a significant main effect of Type of Object (Greenhouse-Geisser correction; $F(1.27,53.48)=10.64, p<$ $\left..001, \eta_{\mathrm{p}}^{2}=.20\right)$, with significantly higher response times for fake $(M=1118.89, S D=576.42)$ compared to new objects, $M=890.13 S D=181.68$, whereas response times for true objects 2 $(M=885.73, S D=242.05)$ were significantly lower than for fake $)$ and new objects.There was also a significant main effect of Session $\left(F(1,42)=18.79, p<.001, \eta_{\mathrm{p}}{ }^{2}=.31\right)$ with higher response times in Session $2(M=1036.53, S D=561.35)$ compared to Session $4(M=$ 878.62,SD=235.92). These results were qualified by a significant interaction between Type of Object and Session (Greenhouse-Geisser correction; $F(1.18,49,61)=7.14, p<.005, \eta_{\mathrm{p}}{ }^{2}=.15$ ). True objects häd lower response time than fake $(t(102)=-3.68, \mathrm{p}<.001$, Cohen's $d=-.36)$ and new objects $(t(102)=-2.48, \mathrm{p}<.05$, Cohen's $d=-.25)$, whereas, fake objects had higher response time than new objects $(t(102)=3.26, p<.01$, Cohen's $d=.32)$. Table 1 shows that while there was a substantial decrease in response times between Session 2 and 4 for fake objects, no change was observed for true and new objects. Post hoc $t$ tests also showed that response times for true and new objects did not differ pre and post debriefing, $(t(60)=1.39, p=.17$ and $\mathrm{t}(60)$ $=1.69, p=.10$; respectively), while fake objects were correctly rejected in Session 4 at a greater speed than in Session 2, $(t(42)=3.5, p<.005$, Cohen's $d=.62)$. 
To further analyze the interaction, we conducted separate ANOVAs and t-tests for Session 2 (pre-debriefing) and Session 4 (post-debriefing). A repeated measures ANOVA for Session 2 data revealed a significant difference in response times across Object Types at session 2 (Greenhouse-Geisser correction; $F(1.17,50.47)=9.09, p<.001, \eta_{\mathrm{p}}^{2}=.18$ ). Not surprisingly, correct recognition for true objects was faster than for fake objects $(t(43)=-2.98$, $p<.05$, Cohen's $d=-.45$ ). Time to correctly reject new objects was not different from correctly accept true objects $(t(60)=-1.58, p=.12$, Cohen's $d=0.20)$. Interestingly, correct rejections for fake objects were slower than for new objects $(t(43)=3.22, p<.05$, Cohen's $d=.49$,), thereby suggesting that false suggestions cannot be easily ignored. All the comparisons were with Bonferroni correction.

The same repeated measures ANOVA at session 4 revealed a significant difference in reaction times across Object Types, (Greenhouse-Geisser correction; $F(1.77,102.53)=4.42, p$ $\left.<.05, \eta_{\mathrm{p}}^{2}=.07\right)$. To account for multiple comparisons, Bonferroni correction was applied. Results revealed that true objects were still recognized faster than fake $(t(58)=-2.86, p<.05$, Cohen's $d=-.38$ ) even after debriefing. RTs for true objects did not differ from new objects $(t(60)=-2.39, p=.20)$. Similarly, on this occasion response times for fake and new objects did not differ $(t(58)=1.07, p=.29)$.

\section{Discussion}

The persistence of false memories for actions over one week, and after an enhanced debriefing, was examined. There are three main findings in this study. First, the results confirm that the doctored videos procedure developed by Nash and colleagues (2009b) produces false memories for actions, as clearly shown by the results in Session 2 (pre-debriefing), in which belief and memory ratings were higher for fake than new objects. While these results replicate the findings by Nash et al. (2009b), in our study the effect of doctored videos on memory is also confirmed by the results obtained in the recognition task, where we found significantly 
lower accuracy for fake objects, which is almost half compared to new objects. These results suggest that the procedure developed by Nash and colleagues significantly affects the decision of the participants in the recognition task.

Second, response times in Session 2 show that even when fake objects are correctly rejected, the responses were slower compared to rejecting new objects. This very interesting result indicates that, even when participants did not report false memories, the doctored video slowed down the decision to reject. This can be due to the presence of memories for fake actions created by the videos, which can be discarded only after a systematic (and thus more time consuming) monitoring of the characteristics of the memory representation (e.g., Johnson et al., 1993). It could also be due to false information interfering with the decision processes during recognition. In any case, the results indicate that false suggestions cannot be easily ignored by the participants.

Third, and most interestingly, the effect of the doctored videos is still evident in Session 4, after the debriefing. In the debriefing (Session 3), participants were told that some specific objects were false and no action was performed on them (see Clark et al., 2012, for a similar procedure). Importantly, the debriefing was enhanced by presenting the participants the correct list of objects once a day after the debriefing until the final test in Session 4, and participants were asked to imagine themselves performing the actions with those objects. This procedure aimed at increasing the effect of debriefing by reminding participants of the true objects with which they had performed an action. Yet, belief and memory ratings remained, on average, higher for fake than for new objects/actions, showing a persistent effect of our false memory manipulation. It should be noted that in addition to the doctored video, between Session 2 and 3 (when the debriefing was given) participants were asked daily to imagine performing both the true and fake actions, and that this imaginative procedure was used to ensure that immediately before debriefing false memories for the fake actions were still present. This 
procedure most likely strengthened the memory for the fake actions, and thus enhanced the persistence of memories even after the enhanced debriefing. Imagery added to the video has an additive effect on false memories (Nash et al., 2009b). It is possible, then, that the long-term false memories obtained in the current study depended also on the added effect of imagination.

However, in an effort to enhance the effectiveness of the debriefing, participants imagined daily, and for a few days, only actions with true objects. The results indicate that imagining only true actions did not achieve the aim of completely discarding false memories. This result is not surprising, as it is well known in the false memory literature that it is much easier to add a false memory than to delete one (see for example Wright \& Loftus, 1998). Similar to that study, in our study false memories are partially resistant to the attempt to discard them by presenting true information. The relative ineffectiveness of the enhanced debriefing is confirmed also by results on accuracy during recognition. Despite the drastic increase in accuracy for fake objects between Sessions 2 (before the debriefing) and 4 (after the debriefing), accuracy remained significantly lower than for new objects. Overall, our results suggest that, at least in some cases, false memories are resistant to the attempt to discard them as false.

Why then did the debriefing not entirely eliminate this type of false memories? Unlike most of the studies examining the persistence of false memories for lists of associated words using the DRM paradigm (see, e.g., McDermott, 1996; Seamon, Luo, Kopecky, Price, Rothschild, Fung, \& Schwartz, 2002; Thapar \& McDermott, 2001; Toglia, Neuschatz, \& Goodwin, 1999), here false memories were for non-performed actions on non-presented objects. In our case, the combination of actions with videos and imagination can create persistent false memories. First, doctored videos increased the plausibility of the suggested false memories. Participants actually observed the researcher performing actions with certain objects. Fake videos may have convinced participants not only that they had observed the 
actions, but because in Session 1 all actions observed had also been performed, that they also had performed the fake actions. Mazzoni and Kirsch (2002) claimed that false memories can be developed if individuals have acknowledged that the false event is highly likely to happen. During the debriefing, a considerable number of participants gave remarks such as, "I thought it was real", "The editing is very good", "I didn't expect that it was actually two videos combined", a strong indication that the fabricated video was really persuasive. Second, fabricated evidence delivered in videos can be rich in sensory details because of the visual information provided. As already mentioned, doctored videos can trick the monitoring system into classifying as a true memory a false item which is rich in perceptual and conceptual details (Johnson, Foley, Suengas, \& Raye, 1988; Lindsay et al., 2004). The Source Monitoring Framework (SMF) is often used to explain how doctored evidence fosters false memories (Johnson et al., 1993; Lindsay, 2008). SMF suggests three cognitive mechanisms: familiarity, imagery, and credibility, to explain how doctored videos fabricate memories. Feelings of familiarity encourage individuals to misattribute suggested events as true memories. In addition, people tend to evaluate information provided by others on the basis of credibility. Doctored evidence is often seen as a credible source of information, indicating that an event had happened (Wade et al., 2002). It might prompt people to adopt a lower memory criterion and acknowledge the content as a true memory. In other words, participants could have willingly considered false memories as being genuine even if less vivid because they had watched them in a video.

Third, we claim that it might also be the nature of actions themselves, and in particular actions on objects, which might also create persistent false memories because of the sensory/motoric activation that is involved. Prior studies have shown that a mere observation of an action can cause an individual to attribute the action to him/herself, a phenomenon called observation inflation (Lindner, Echterhoff, Davidson, \& Brand, 2010). According to this 
phenomenon, observing an action causes an increase in familiarity (Thomas, Bulevich, \& Loftus, 2003) and it also provides perceptual and contextual cues that can be misattributed as self- performed, especially when rigorous source monitoring is lacking (Johnson et al., 1993). Moreover, the motor representation of the observer matches the person executing the action, suggesting that a "covert" simulation of action occurs, which recruits neural structures similar to those involved in the actual action execution (Buccino et al., 2001; Wilson \& Knoblich, 2005). On the basis of this literature one could expect false beliefs for actions involving objects to be stronger than false beliefs for other types of material, and as such also more resistant to debriefing. The neurocognitive literature on action observation also highlights the importance of visually displaying the object. Studies on the mirror system indicate an activation on mirror neurons, especially in mirror areas of the pre-motor cortex, both when performing specific actions or during action observation (Di Pellegrino, Fadiga, Fogassi, Gallese, \& Rizzolatti, 1992; Gallese, Fadiga, Fogassi, \& Rizzolatti, 1996; Hari et al., 1998; Rizzolatti, Fadiga, Gallese, \& Fogassi, 1996). In addition, some areas are selective for specific types of actions, like object/related actions. Observation of object-related actions results in a strong somatotopical activation on the posterior parietal lobe (for a complete review see, e.g., Caspers, Zilles, Laird, \& Eickhoff, 2010), and even the mere observation of an object, as well as merely reading the object's name, can trigger the feeling of action (see, e.g., Tucker \& Ellis, 2004).

Last, as already mentioned, we also tried to strengthen the memory by asking our participants to "think" of performing an action with the objects for a couple of days before the debriefing. Repeated imagination is a well-established way of inducing false memories (Garry et al., 1996; Goff \& Roediger, 1998; Lindner et al., 2010; Mazzoni \& Memon, 2003). Imagined events are highly likely to be attributed as true memories especially if they are easy to imagine (Finke, Johnson, \& Shyi, 1988; Johnson, Raye, Wang, \& Taylor, 1979). Imagining actions 
might be even more influential, as it is a kinematic representation that typically involves selfgeneration, a process that can enhance false memories (Sharman, Manning, \& Garry, 2005).

Repeated imagination and presentation of doctored evidence are proven to be effective tools for false memory implantation. When combined, they can lead to false memories that are more persistent even after the debriefing. All these components (videos, imagination, actions) might have interacted, thus increasing the strength of these false memories and making them more resistant to the enhanced debriefing. Our study confirmed that fabricated videos and imagination create persistent false memories (Nash et al., 2009b), persistent enough to resist specific debriefing. While subsequent studies are necessary to disentangle the contribution of each component, one conclusion we can draw from this study is that it is necessary to take into account the nature of the processes involved in the creation of false memories, as these processes might determine their strength over time as well as their resistance to debriefing.

We also examined the existence of NBMs on multiple recent actions using this procedure. Unlike previous studies (e.g., Clark et al., 2012), in the current study the debriefing did not decrease beliefs more than memories and thus a very small number of non-believed memories were obtained. There are several potential explanations for this difference in results. We administered the belief questionnaire first, while Clark et al. (2012) presented it after the memory questionnaire. Rating the belief first might have influenced the memory rating. It is also possible that in the language of the participants (Turkish), the distinction between belief and memory in daily context is less clear. Using belief in reference to memory is not a common practice, thus participants might not have fully understood the difference between belief and memory, which indeed received very similar ratings. One can also argue, however, that, unlike Clark et al. (2012), on which we based the current study, the actions used in our study involved objects. The presence of objects could reinforce the "motoric component" of the memory trace (see. e.g., Tucker \& Ellis, 1998) which is known to be a crucial factor for its memorability (see, 
e.g., Engelkamp, 2001; Ianì \& Bucciarelli, 2017; 2018; Hilverman, Cook, \& Duff, 2018) and thus make them more believable and experienced as true (which is reflected in the belief rating).

Although debriefing did not result in non-believed memories, it had a significant effect on response times. In Session 4, fake objects were correctly rejected at a similar speed as new objects, while before the debriefing rejection times were significantly higher for fake than new objects. Although debriefing did not eliminate false memories, it seemingly had at least the effect of facilitating the decision when recognizing an object as fake and hence not originally presented. The effect of the debriefing on decision times is not in contrast with false memories persistence. We remind that overall many more false memories were correctly rejected after the debriefing, compared to before the debriefing. These correct rejections were made rather quickly for those false memories that people considered to be false. The effect on response times might be driven by the large number of correct rejections. However, one could speculate that decisions might have been rather fast also when accepting false memories as true. This possibility will be examined in a future study.

Our results have relevant practical implications. First, assessing the cognitive effects of false evidence (both pre- and post- debriefing) is especially pertinent to the guidelines used during the interrogation of criminal suspects. Police investigators in some countries of the world are allowed to use false evidence in order to elicit a confession (for a discussion see, e.g., Gudjonsson, 2003). In light of our results, such error-prone or even false evidence can easily create memories that resist denial and clear debriefing. And, second, our results shed light on the possible consequences of using image/video manipulations in everyday life. We tend to believe what we see, but new technologies are increasingly blurring the line between fact and fiction (for instance, it has been suggested that many images posted on social networks are doctored; Ottke \& Adam, 2015). Our results indicate that image/video manipulations can easily cause people to believe in something which is false. As pointed out by Wade et al. (2002), 
"although doctoring personal photos may appear to be pure entertainment, the research [...] shows that exposure to altered photographs can lead to false memories" (p.597).

\section{Conclusion}

One of the necessary conclusions of this study is that the paradigm ideated by Nash and colleagues $(2009 \mathrm{~b})$ is able to induce false memories that affect the decision of the participants in a recognition task. Second, one needs to be careful when presenting doctored videos, as the effect is not only long-lasting (one week), but for some memories it is rather persistent even after clear and specific disconfirmatory information is presented. Furthermore, our results shed light on cognitive mechanisms that take place when suggestions fail to create accepted false memories. Even in this case participants struggle to ignore the false information, thereby suggesting that a "covert false information" is still present. Future studies could investigate whether such cognitive processes can be considered the first step for a spontaneous development of future false memories. It is also worth revisiting other areas of research such as false confessions, misinformation effects and how people evaluate and re-evaluate the occurrence of events in light of our results. 


\section{Appendix A}

\section{List of Pre-determined Objects}

1. Little cup

2. Teaspoon

3. Fork

4. Mug

5. Knife (breadknife)

6. Toothbrush

7. Comb

8. Scissors

9. Eraser

10. Glove

11. Wristwatch

12. Glasses

13. Whisk

14. Small box

15. Scarf

16. Pencil

17. Mobile Phone

18. Keys

19. Lighter

20. Book

21. Mouse

22. Hammer

23. Paintbrush

24. Thimble

25. Salt cellar

26. Hat

27. Wrench

28. Screwdriver

29. Spray

30. Nail

31. Paperclip

32. Corkscrew

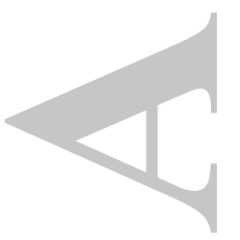




\section{References}

Bartlett, F. C. (1932). Remembering: A study in experimental and social psychology. Cambridge,

England: Cambridge University Press. doi:10.1111//j.2044-8279.1933.tb02913.x

Brewer, W. F. \& Treyens, J. C. (1981). Role of schemata in memory for places. Cognitive Psychology, 13, 207-230. doi:10.1016/0010-0285(81)90008-6

Bruck, M., Ceci, S. J., \& Hembrooke, H. (1998). Reliability and credibility of young children's reports: From research to policy and practice. American Psychologist, 53,136-151. doi:10.1037/0003-066x.53.2.136

Buccino, G., Binkofski, F., Fadiga, L., Fogassi, L., Gallese, V., Seitz, R. J., ... Freund, H. J. (2001). Action observation activates premotor and parietal areas in somatotopic manner: An fMRI study. European Journal of Neuroscience, 13, 400-404. doi:10.1111/j.14609568.2001.01385.x

Caspers, S., Zilles, K., Laird, A. R., \& Eickhoff, S. B. (2010). ALE meta-analysis of action observation and imitation in the human brain. Neuroimage, 50, 1148-1167. doi:10.1016/j.neuroimage.2009.12.112

Ceci, S. J., Huffman, M. L. C., Smith, E., \& Loftus, E. F. (1994). Repeatedly thinking about a non-event: Source misattributions among preschoolers. Consciousness and Cognition, 3(3-4), 388-407. doi:10.1006/ccog.1994.1022

Clark, A., Nash, R. A., Fincham, G., \& Mazzoni, G. (2012). Creating non-believed memories for recent autobiographical events. PLoS One, 7(3). doi:10.1371/journal.pone.0032998

Conway, M. A. (Ed.). (1997). Recovered memories and false memories. Oxford, England: Oxford University Press. doi:10.1093/med:psych/9780198523864.001.0001 
Chrobak, Q. M. \& Zaragoza, M. S. (2013). When forced fabrications become truth: Causal explanations and false memory development. Journal of Experimental Psychology: General, $\quad$ 142, 827-844. doi:10.1037/a0030093

Di Pellegrino, G., Fadiga, L., Fogassi, L., Gallese, V., \& Rizzolatti, G. (1992). Understanding motor events: A neurophysiological study. Experimental Brain Research, 91, 176-180. doi: $10.1007 / \mathrm{bf} 00230027$

Engelkamp, J. (2001). Action memory: A system oriented approach. In H. D. Zimmer, R. L. Cohen, M. J. Guynn, J. Engelkamp, R. Kormi-Nouri, \& M. A. Foley (Eds.), Memory for action: A distinct form of episodic memory? (pp. 4996). New York, NY: Oxford University Press.

Finke, R. A., Johnson, M. K., \& Shyi, G. C. (1988). Memory confusions for real and imagined completions of symmetrical visual patterns. Memory and Cognition, 16,133-137.doi: $10.3758 / \mathrm{bf03213481}$

Fisher, R.P., Geiselman, R.E., \& Raymond, D.S. (1987). Critical analysis of police interviewing techniques. Journal of Police Science and Administration, 15, 177-185.

Gallese, V., Fadiga, L., Fogassi, L., \& Rizzolatti, G. (1996). Action recognition in the premotor cortex. Brain, 119, 593-609. doi:10.1093/brain/119.2.593

Garry, M., Manning, C. G., Loftus, E. F., \& Sherman, S. J. (1996). Imagination inflation: Imagining a childhood event inflates confidence that it occurred. Psychonomic Bulletin \& Review, 3, 208-214. doi:10.3758/bf03212420

Green, D. M., \& Swets, J. A. (1966). Signal detection theory and psychophysics. New York:

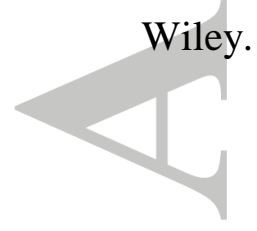


Goff, L. M. \& Roediger, H. L. (1998). Imagination inflation for action events: Repeated imaginings lead to illusory recollections. Memory \& Cognition, 26, 20-33. doi:10.3758/bf03211367

Gudjonsson, G. H. (2003). The psychology of interrogations and confessions: A handbook. New York: NY: Wiley \& Sons. doi:10.1002/9780470713297

Hannigan, S. L. \& Tippens Reinitz, M. (2001). A demonstration and comparison of two types of inference-based memory errors. Journal of Experimental Psychology: Learning, Memory, and Cognition, 27(4), 931-940. doi:10.1037//0278-7393.27.4.931

Hari, R., Forss, N., Avikainen, S., Kirveskari, E., Salenius, S., \& Rizzolatti, G. (1998). Activation of human primary motor cortex during action observation: A neuromagnetic study. Proceedings of the National Academy of Sciences, 95(25), 15061-15065. doi:10.1073/pnas.95.25.15061

Hart, R. E. \& Schooler, J. W. (2006). Increasing belief in the experience of an invasive procedure that never happened: The role of plausibility and schematicity. Applied Cognitive Psychology, 20 (5), 661-669. doi:10.1002/acp.1218

Hautus, M. J. (1995). Corrections for extreme proportions and their biasing effects on estimated values of d'.Behavior Research Methods, Instruments, \& Computers, 27(1), 46-51. doi:10.3758/bf03203619

Hilverman, C., Cook, S. W., \& Duff, M. C. (2018). Hand gestures support word learning in patients with hippocampal amnesia. Hippocampus, 28(6), 406-415. doi:10.1002/hipo.22840

Huffman, M. L., Crossman, A. M., \& Ceci, S. J. (1997). “Are false memories permanent?”: An investigation of the long-term effects of source misattributions. Consciousness and Cognition, 6(4), 482-490. doi:10.1006/ccog.1997.0316 
Hyman, I. E., Husband, T. H., \& Billings, F. J. (1995). False memories of childhood experiences. Applied

doi:10.1002/acp.2350090302

Ianì, F., \& Bucciarelli, M. (2017). Mechanisms underlying the beneficial effect of a speaker's gestures on the listener. Journal of Memory and Language,96, 110-121. doi:10.1016/j.jml.2017.05.004

Ianì, F., \& Bucciarelli, M. (2018). Relevance of the listener's motor system in recalling phrases enacted by the speaker. Memory, 26(8), 1084-1092. doi:10.1080/09658211.2018.1433214

Johnson, M. K., Foley, M. A., Suengas, A. G., \& Raye, C. L. (1988). Phenomenal characteristics of memories for perceived and imagined autobiographical events. Journal of Experimental Psychology: General,117(4) , 371-376. doi:10.1037/00963445.117 .4 .371

Johnson, M. K., Hashtroudi, S., \& Lindsay, D. S. (1993). Source monitoring. Psychological Bulletin, 114, 3-28. doi:10.1037/0033-2909.114.1.3

Johnson, M.K., \& Raye, C.L. (2000). Cognitive and brain mechanisms of false memories and beliefs. In Schacter, D. L. \& Scarry, E., Memory, Brain, and Belief (Eds), pp. 25-86, Harvard University Press.

Johnson, M. K., Raye, C. L., Wang, A. Y., \& Taylor, T. T. (1979). Fact and fantasy: the roles of accuracy and variability in confusing imaginations with perceptual experiences. Journal of Experimental Psychology: Human Learning and Memory, 5(3) , 229-240. doi:10.1037//0278-7393.5.3.229

Kassin, S. M., Drizin, S. A., Grisso, T., Gudjonsson, G. H., Leo, R. A., \& Redlich, A. D. (2010). Police- induced confessions: Risk factors and recommendations. Law and Human 
Behavior,

34, 3-38. doi: 10.1007/s10979-009-9188-6

Kassin, S. M., \& Gudjonsson, G. H. (2004). The psychology of confessions: A review of the literature and issues. Psychological Science in the Public Interest, 5, 33-67. doi: 10.1111/j.1529-1006.2004.00016.x

Katz, A.N. (1989). Autobiographical memory as a reconstructive process. Canadian Journal of Psychology, 43, 512-517. doi: 10.1037/h0084232

Laney, C., \& Loftus, E. F. (2013). Recent advances in false memory research. South African Journal of Psychology, 43(2), 137-146. doi:10.1177/0081246313484236

Leo, R. A. \& Davis, D. (2010). From false confession to wrongful conviction: Seven psychological processes. Journal of Psychiatry \& Law, 38(1-2), 9-56. doi: $10.1177 / 009318531003800103$

Lindner, I., Echterhoff, G., Davidson, P. S., \& Brand, M. (2010). Observation inflation: Your actions become mine. Psychological Science,21, 1291-1299. doi: $10.1177 / 0956797610379860$

Lindsay, D. S. (2008). Source Monitoring. In: Byrne J, Roediger HL III, (Eds.), Cognitive psychology of memory. Learning and memory: A comprehensive reference. Vol. 2. (pp. 325-348). Oxford, England: Elsevier.

Lindsay, D. S., Hagen, L., Read, J. D., Wade, K. A., \& Garry, M. (2004). True photographs and false memories. Psychological Science, 15(3), 149-154. doi:10.1111/j.09567976.2004.01503002.x

Loftus, E. F. (1979). Eyewitness testimony. Cambridge, MA: Harvard University Press.

Loftus, E. F. \& Palmer, J. E. (1974). Reconstruction of automobile destruction: An example of the interaction between language and memory. Journal of Verbal Learning and Verbal Behavior, 13(5), 585-589. doi:10.1016/S0022-5371(74)80011-3 
Loftus, E. F. \& Pickrell, J. E. (1995). The formation of false memories. Psychiatric Annals, 25(12), 720-725. doi:10.3928/0048-5713-19951201-07

Loftus, E. F. (2005). Planting misinformation in the human mind: A 30-year investigation of the

malleability of memory. Learning \& Memory, 12(4), 361-366. doi:10.1101/lm.94705

Mazzoni, G., Clark, A., \& Nash, R. A. (2014). Disowned recollections: Denying true experiences undermines belief in occurrence but not judgments of remembering. Acta Psychologica, 145, 139-146. doi:10.1016/j.actpsy.2013.11.007

Mazzoni, G. A., Loftus, E. F., \& Kirsch, I. (2001). Changing beliefs about implausible autobiographical events: A little plausibility goes a long way. Journal of Experimental Psychology: Applied, 7(1), 51-59. doi:10.1037//1076-898x.7.1.51

Mazzoni, G. A., Loftus, E. F., Seitz, A., \& Lynn, S. J. (1999). Changing beliefs and memories through dream interpretation. Applied Cognitive Psychology. 13(2) , 125-144. doi:10.1002/(sici)1099-0720(199904)13:23.3.co;2-X

Mazzoni, G. \& Kirsch, I. (2002). Autobiographical memories and beliefs: A preliminary metacognitive model. In T. J. Perfect \& B. L. Schwartz (Eds.), Applied Metacognition (pp. 121-145). Cambridge, UK: Cambridge University Press. doi:10.1017/cbo9780511489976.007

Mazzoni, G. \& Memon, A. (2003). Imagination can create false autobiographical memories. Psychological Science, 14(2),186-188 doi:10.1046/j.14321327.2000.01821.x

Mazzoni, G., Scoboria, A., \& Harvey, L. (2010). Non-believed memories. Psychological Science, 21(9) , 1334-1340. doi:10.1177/0956797610379865 
McCloskey, M., \& Zaragoza, M. (1985). Misleading postevent information and memory for events: Arguments and evidence against memory impairment hypotheses. Journal of Experimental Psychology: General, 114(1), 1-16. doi:10.1037//0096-3445.114.1.1

McDermott, K. B. (1996). The persistence of false memories in list recall. Journal of Memory and Language, 35(2), 212-230. doi:10.1006/jmla.1996.0012

Nash, R. A., Wade, K. A., \& Brewer, R. J. (2009a). Why do doctored images distort memory? Consciousness and Cognition, 18(3), 773-780. doi:10.1016/j.concog.2009.04.011

Nash, R. A., Wade, K. A., \& Lindsay, D. S. (2009b). Digitally manipulating memory: Effects of doctored videos and imagination in distorting beliefs and memories. Memory \& Cognition, 37(4), 414-424. doi:10.3758/mc.37.4.414

Otgaar, H., Candel, I., Merckelbach, H., \& Wade, K. A. (2009). Abducted by a UFO: Prevalence information affects young children's false memories for an implausible event. Applied Cognitive Psychology: The Official Journal of the Society for Applied Research in Memory and Cognition, 23(1), 115-125. doi:10.1002/acp.1445

Otgaar, H., Scoboria, A., \& Smeets, T. (2013). Experimentally evoking nonbelieved memories for childhood events. Journal of Experimental Psychology: Learning, Memory, and Cognition, 39 (3), 717-730. doi:10.1037/a0029668

Ottke, A., \& Adam. (2015, November 11). 68 Percent of Adults Edit Their Selfies Before Sharing Them With Anyone. Retrieved from https://fstoppers.com/mobile/68-percentadults-edit-their-selfies-sharing-them-anyone-95417

Rizzolatti, G., Fadiga, L., Gallese, V., \& Fogassi, L. (1996). Premotor cortex and the recognition of motor actions. Cognitive Brain Research, 3 (2), 131-141. doi:10.1016/0926-6410(95)00038-0

Schacter, D.L., Coyle, J.T., Fischbach, G.D., Mesulam, M.M., \& Sullivan, L.E (Eds.). (1995). Memory Distortions: How minds, brains, and societies reconstruct the past. Cambridge, 
MA: Harvard University Press.

Scoboria, A., Boucher, C., \& Mazzoni, G. (2015). Reasons for withdrawing belief in vivid autobiographical memories. Memory, 23(4) 545562. doi:10.1080/09658211.2014.910530

Scoboria, A., Mazzoni, G., Kirsch, I., \& Milling, L. S. (2002). Immediate and persisting effects of misleading questions and hypnosis on memory reports. Journal of Experimental Psychology: Applied, 8(1), 26-32. doi:10.1037//1076-898x.8.1.26

Scoboria, A., Mazzoni, G., Kirsch, I., \& Relyea, M. (2004). Plausibility and belief in autobiographical memory. Applied Cognitive Psychology, 18(7), 791-807. doi:10.1002/acp.1062

Seamon, J. G., Luo, C. R., Kopecky, J. J., Price, C. A., Rothschild, L., Fung, N. S., \& Schwartz, M. A. (2002). Are false memories more difficult to forget than accurate memories? The effect of retention interval on recall and recognition. Memory \& Cognition, 30(7), 10541064. doi:10.3758/bf03194323

Sharman, S. J., Manning, C. G., \& Garry, M. (2005). Explain this: Explaining childhood events inflates confidence for those events. Applied Cognitive Psychology, 19(1), 67-74. doi:10.1002/acp.1041

Shaw, J. \& Porter, S. (2013). Constructing Rich False Memories of Committing Crime. PsycEXTRA Dataset. doi:10.1037/e571212013-048.

Thapar, A. \& McDermott, K. B. (2001). False recall and false recognition induced by presentation of associated words: Effects of retention interval and level of processing. Memory \& Cognition, 29(3), 424-432. doi:10.3758/bf03196393

Thomas, A.K., Bulevich, J.B., \& Loftus, E.F. (2003). Exploring the role of repetition and sensory elaboration in the imagination inflation effect. Memory \& Cognition, 31(4), 630640. 
doi:10.3758/bf03196103

Toglia, M. P., Neuschatz J. S., \& Goodwin K. A. (1999). Recall accuracy and illusory memories: When more is less. Memory, 7(2), 233-256. doi:10.1080/741944069

Tucker, M. \& Ellis, R. (1998). On the relations between seen objects and components of potential actions. Journal of Experimental Psychology: Human Perception and Performance, 24(3), 830-846. doi:10.1037//0096-1523.24.3.830

Tucker, M. \& Ellis, R. (2004). Action priming by briefly presented objects. Acta Psychologica, 116(2), 185-203. doi:10.1016/s0001-6918(04)00019-8

Wade, K. A., Garry, M., Read, J. D., \& Lindsay, D. S. (2002). A picture is worth a thousand lies: Using false photographs to create false childhood memories. Psychonomic Bulletin \& Review, 9(3), 597-603. doi:10.3758/bf03196318

Wilson, M. \& Knoblich, G. (2005). The case for motor involvement in perceiving conspecifics. Psychological Bulletin, 131(3), ～460-473.doi:10.1037/00332909.131.3.460

Wright, D. B., \& Loftus, E. F. (1998). How misinformation alters memories. Journal of Experimental Child Psychology, 71(2), 155-164. doi:10.1006/jecp.1998.2467

Zaragoza, M. S., Payment, K. E., Ackil, J. K., Drivdahl, S. B., \& Beck, M. (2001). Interviewing witnesses: Forced confabulation and confirmatory feedback increase false memories. Psychological Science, 12(6), 473-477. doi:10.1111/1467-9280.00388

Zhu, B., Chen, C., Loftus, E. F., He, Q., Chen, C., Lei, X., Lin, C. \& Dong, Q. (2012). Brief exposure to misinformation can lead to long- term false memories. Applied Cognitive Psychology, 26(2), 301-307. doi:10.1002/acp.1825

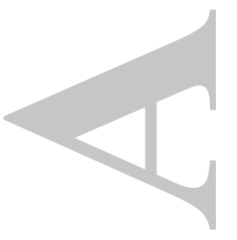


Table 1. Mean Belief, Memory, Accuracy (d') Ratings and Response Times for Correct

Responses pre and post-debriefing. Confidence intervals are also reported.

\begin{tabular}{|c|c|c|c|c|c|c|c|c|c|c|}
\hline & & \multicolumn{2}{|c|}{ Pre debriefing } & \multicolumn{4}{|c|}{$\begin{array}{c}\text { Post } \\
\text { debriefing }\end{array}$} & \multirow[b]{2}{*}{$95 \% L C L$} & & \multirow[t]{2}{*}{ Significance } \\
\hline & & $M$ & $S D$ & $\begin{array}{l}95 \% \\
L C L\end{array}$ & $\begin{array}{l}95 \% \\
U C L\end{array}$ & $M$ & $S D$ & & $\begin{array}{l}95 \% \\
U C L\end{array}$ & \\
\hline \multirow[t]{3}{*}{ Belief } & True & 7.51 & 0.99 & 7.26 & 7.76 & 7.55 & 0.94 & 7.31 & 7.8 & n.s. \\
\hline & Fake & 4.49 & 2.63 & 3.81 & 5.16 & 1.99 & 1.66 & 1.56 & 2.41 & $* *$ \\
\hline & New & 2.29 & 2.09 & 1.75 & 2.83 & 1.21 & 0.89 & 0.98 & 1.44 & $* *$ \\
\hline \multirow[t]{3}{*}{ Memory } & True & 7.49 & 0.89 & 7.26 & 7.72 & 7.52 & 0.97 & 7.27 & 7.77 & $n . s$. \\
\hline & Fake & 4.35 & 2.74 & 3.65 & 5.05 & 1.86 & 1.49 & 1.48 & 2.25 & $* *$ \\
\hline & New & 2.27 & 2.19 & 1.71 & 2.84 & 1.13 & 0.59 & 0.98 & 1.28 & $* *$ \\
\hline \multirow[t]{2}{*}{ Accuracy } & True-Fake & 1.47 & 1.34 & 1.13 & 1.81 & 2.62 & 0.84 & 2.4 & 2.83 & $* *$ \\
\hline & $\begin{array}{l}\text { True- } \\
\text { New }\end{array}$ & 2.8 & 0.8 & 2.59 & 3 & 2.9 & 0.56 & 2.76 & 3.05 & n.s. \\
\hline \multirow[t]{3}{*}{$\begin{array}{l}\text { Response } \\
\text { times }\end{array}$} & True & 938.66 & $\begin{array}{c}286.2 \\
5\end{array}$ & 850.57 & $\begin{array}{c}1026.7 \\
6\end{array}$ & 832.8 & $\begin{array}{c}197.8 \\
4\end{array}$ & 771.91 & $\begin{array}{c}893.6 \\
9\end{array}$ & $n . s$ \\
\hline & Fake & 1333.2 & $\begin{array}{c}900.1 \\
1\end{array}$ & $\begin{array}{c}1056.1 \\
9\end{array}$ & $\begin{array}{c}1610.2 \\
1\end{array}$ & 904.58 & $\begin{array}{c}252.7 \\
3\end{array}$ & 826.8 & $\begin{array}{c}982.3 \\
6\end{array}$ & $*$ \\
\hline & New & 915.72 & $\begin{array}{c}152.9 \\
6\end{array}$ & 868.65 & 962.79 & 864.53 & $\begin{array}{c}210.4 \\
1\end{array}$ & 799.78 & $\begin{array}{c}929.2 \\
9\end{array}$ & n.s. \\
\hline
\end{tabular}




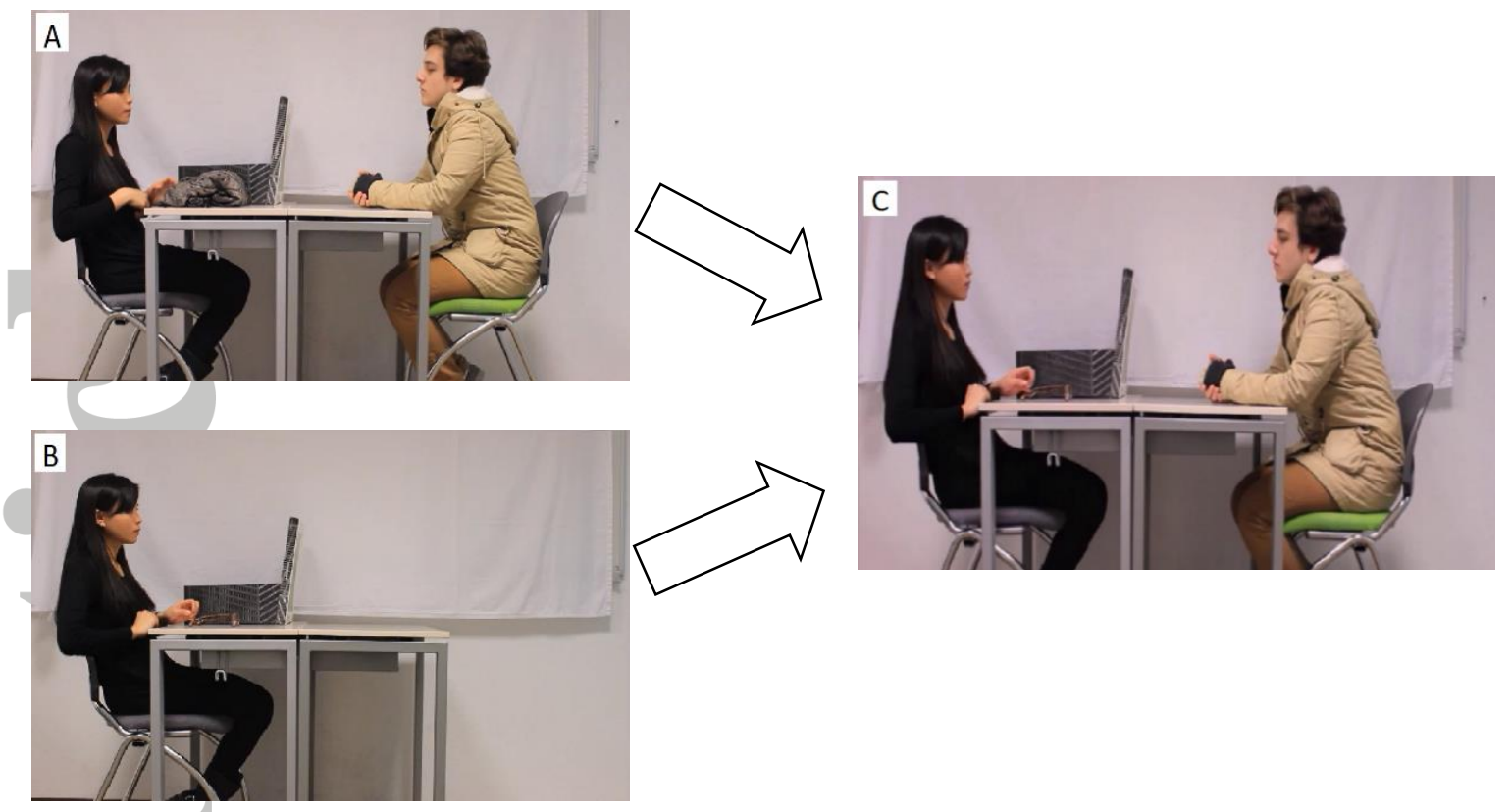

Figure 1. Video manipulation. (A) Real clip. (B) Fake action. (C) Doctored composite of (A) and (B).

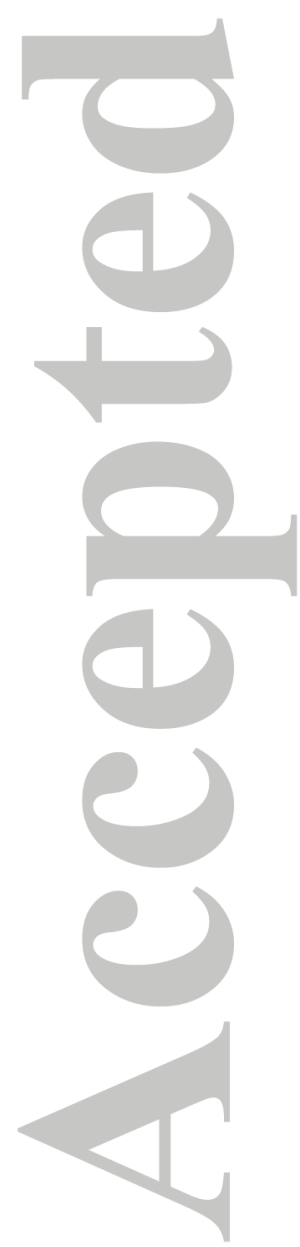

